\title{
Complications of Nasoseptal Flap Reconstruction: A Systematic Review
}

\author{
Philippe Lavigne $^{1}$ Daniel L. Faden ${ }^{1} \quad$ Eric W. Wang ${ }^{1}$ Carl H. Snyderman ${ }^{1}$ \\ ${ }^{1}$ Department of Otolaryngology, University of Pittsburgh Medical \\ Center, Pittsburgh, Pennsylvania, United States \\ J Neurol Surg B 2018;79(suppl S4):S291-S299.

\begin{abstract}
Address for correspondence Carl H. Snyderman, MD, MBA, Center for Cranial Base Surgery, University of Pittsburgh Medical Center, 200 Lothrop St. Eye and Ear Institute Suite 500, Pittsburgh, PA 15213, United States (e-mail: snydermanch@upmc.edu).
\end{abstract}

\begin{abstract}
Objective The nasoseptal flap (NSF) is considered the primary vascularized flap for reconstruction of dural defects with endoscopic endonasal surgery (EES) of the skull base. However, the complications and morbidities associated with this reconstructive flap are poorly understood. This article presents a systematic review of the complications and morbidities related to the use of the NSF in skull base surgery.

Method A systematic review of the literature based on published guidelines was performed to identify potential complications and morbidities related to the NSF. The MEDLINE and Embase databases were searched from January 1, 1950 to February 5, 2018.

Results Twenty-seven articles were identified. Reported complications were as

\section{Keywords}

- systematic review

- skull base surgery

- nasoseptal flap

- complications

- reconstruction follows: NSF necrosis (4 studies; [0-1.3\%]), mucocele formation (5 studies; [0-3.6\%]), septal perforation (6 studies, [0-14.4\%]), nasal dorsum collapse ( 2 studies, [0.7-5.8\%]), effects on quality of life (QoL) (8 studies), and olfactory loss (11 studies). Conclusion Although complications associated with the NSF may be underreported in the literature, the NSF appears to be a safe and reliable reconstructive flap in EES of the skull base.
\end{abstract}

\section{Introduction}

The nasoseptal flap (NSF), also named Hadad flap, was described in 2006 and was rapidly adopted as the primary reconstructive method for reconstruction in endoscopic endonasal surgery (EES) of the skull base. ${ }^{1}$ Initial reports of using a U-shaped flap of three-fourth of the septal mucoperichondrial layer was initially described by Hirsch in 1952; however, it is not clear from the description that this flap had axial vascular supply. ${ }^{2}$ The NSF is widely considered a robust and reliable vascularized flap, with a wide variety of applications. Reconstruction of large dural defects with vascularized tissue, as part of a multilayer reconstruction, was found to significantly reduce the rate of cerebrospinal fluid (CSF) leak rates from 15.6 to $6.7 \%$ compared with nonvascularized reconstruction. ${ }^{3}$ In a single institution study that included 70 consecutive NSF for reconstruction

received

April 30, 2018

accepted after revision

July 7, 2018

published online

August 20, 2018 of high-flow CSF leaks, the NSF was found to have a $94 \%$ efficacy rate. ${ }^{4}$ Several studies have now described the postoperative complications and morbidity associated with this flap. While there are single institution reports of the complications associated with NSFs, no comprehensive reviews exist to describe the full scope and frequency of such complications across surgeons and institutions. Here, we present a systematic review of the published literature regarding complications and morbidities related to the NSF.

\section{Methods}

A systematic review of published literature was performed for the primary outcome of NSF complications and morbidities. The MEDLINE and Embase databases were searched from January 1, 1950 to February 5, 2018. - Table 1 presents
DOI https://doi.org/ 10.1055/s-0038-1668158. ISSN 2193-6331. (c) 2018 Georg Thieme Verlag KC Stuttgart · New York 
Table 1 Systematic review search strategy

\begin{tabular}{|l|l|}
\hline Themes & MeSH term used in search strategy \\
\hline 1 & $\begin{array}{l}\text { Endoscopy, endoscope, skull base surgery, sino- } \\
\text { nasal, and cranial base surgery }\end{array}$ \\
\hline 2 & $\begin{array}{l}\text { Reconstruction, reconstructive surgical proce- } \\
\text { dures, surgical flaps, tissue and organ harvest- } \\
\text { ing, nasoseptal flap, and Hadad flap }\end{array}$ \\
\hline 3 & $\begin{array}{l}\text { Adverse effects, postoperative complications, } \\
\text { and complication }\end{array}$ \\
\hline
\end{tabular}

the MeSH terms that were used in the search strategy. The bibliographies of identified articles were also reviewed for additional relevant articles. After the search was completed, study selection was performed by abstract review by the first author (Philippe Lavigne). Data extraction was reviewed for accuracy by the second author. Discrepancies between reviewers were resolved via discussion with a third reviewer. When available, individual patient data were extracted. Only published articles in English were included. Case reports and case series with less than five reported cases were excluded. Only studies with data specific to the use of the NSF were included for final analysis.

\section{Results}

Initial database search produced 2,403 studies. A title search found 406 articles on the NSF. After abstract review, 27 articles were included for the final analysis. The selection process is outlined in - Fig. 1 . The identified complications related to the use of the NSF were as follows: NSF necrosis, mucocele formation, septal perforation, nasal dorsum collapse, reduced quality of life (QoL), and olfactory loss. - Tables 2-4 present the included articles for each identified complication.

\section{Nasoseptal Flap Necrosis}

Chabot et al presented a series of 601 consecutive NSF, of which $8(1.3 \%)$ were found to have NSF necrosis on re- exploration (-Fig. 2). ${ }^{5}$ All patients with NSF necrosis presented with signs or symptoms of meningitis at least 1 week after their initial surgery, and 50\% were found to have empyema at the surgical bed. All patients with necrotic flaps had undergone contrast-enhanced magnetic resonance imaging (MRI) in the initial immediate postoperative period, and flap enhancement was absent in seven of eight cases. One case showed thin peripheral enhancement, but intraoperative exploration revealed a partly necrotic flap and required debridement. Prior intranasal surgery (with narrowed flap pedicle) was identified as a risk factor for NSF necrosis in this series. In their series of 144 NSF, Thorp et al identified no cases of perioperative complete flap loss. ${ }^{8}-$ Table $_{2}$ presents additional studies that reported NSF necrosis rates.

\section{Mucocele Formation}

Mucocele formation is not a complication of the NSF itself, but the result of incomplete removal of sphenoid mucosa on the recipient bed. Bleier et al published an article on the rate of mucocele formation after NSF reconstruction with localized mucosal stripping (mucosa around the defect was left intact). ${ }^{11}$ Twenty-eight patients were included, and after a mean follow-up of 8 months, only one (3.6\%) patient developed a mucocele. Similarly, Soudry et al identified one $(0.8 \%)$ case of mucocele 2 years after the initial surgery. ${ }^{7}$ The patient was asymptomatic, but due to radiological evidence of enlargement, the mucocele was surgically drained. The other identified studies found a $0 \%$ rate of mucocele formation (-Table 2).

\section{Olfactory Change}

Upadhyay et al compared University of Pennsylvania Smell Identification Test (UPSIT) scores between patients who had reconstruction of skull base defects with an NSF (10 patients) and patients who had free mucosal graft reconstruction (35 patients). ${ }^{18}$ The UPSIT scores were compared at baseline, 6 weeks, 3 months, and 6 months postoperatively. The authors found a significant reduction in UPSIT scores in the NSF group at 6 weeks $(24.5 \pm 5.4)$ when compared with

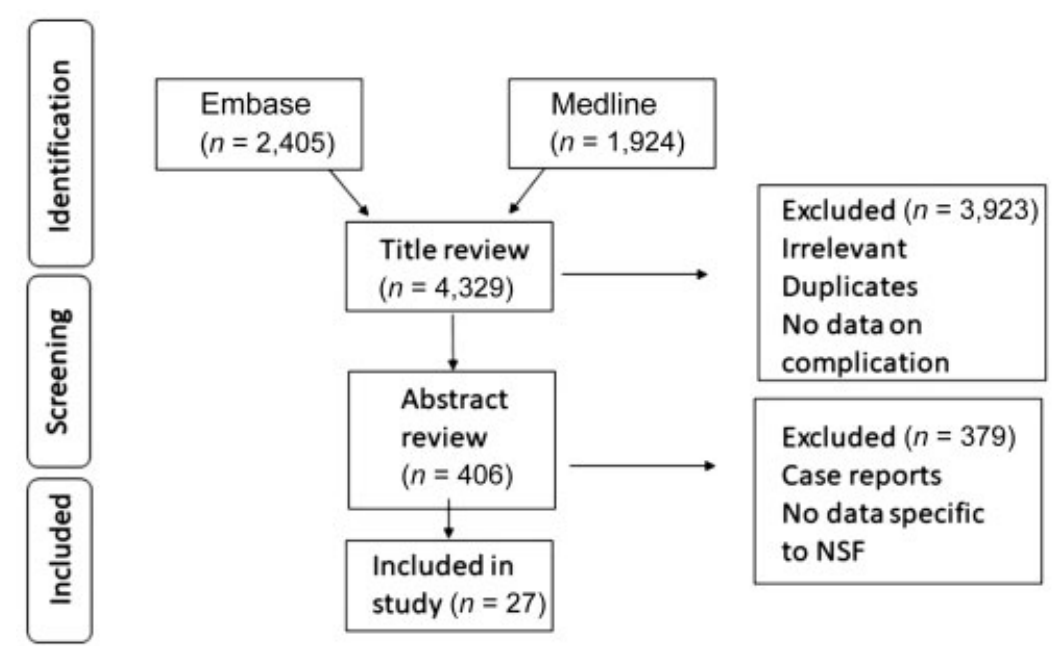

Fig. 1 Article selection process. NSF, nasoseptal flap. 


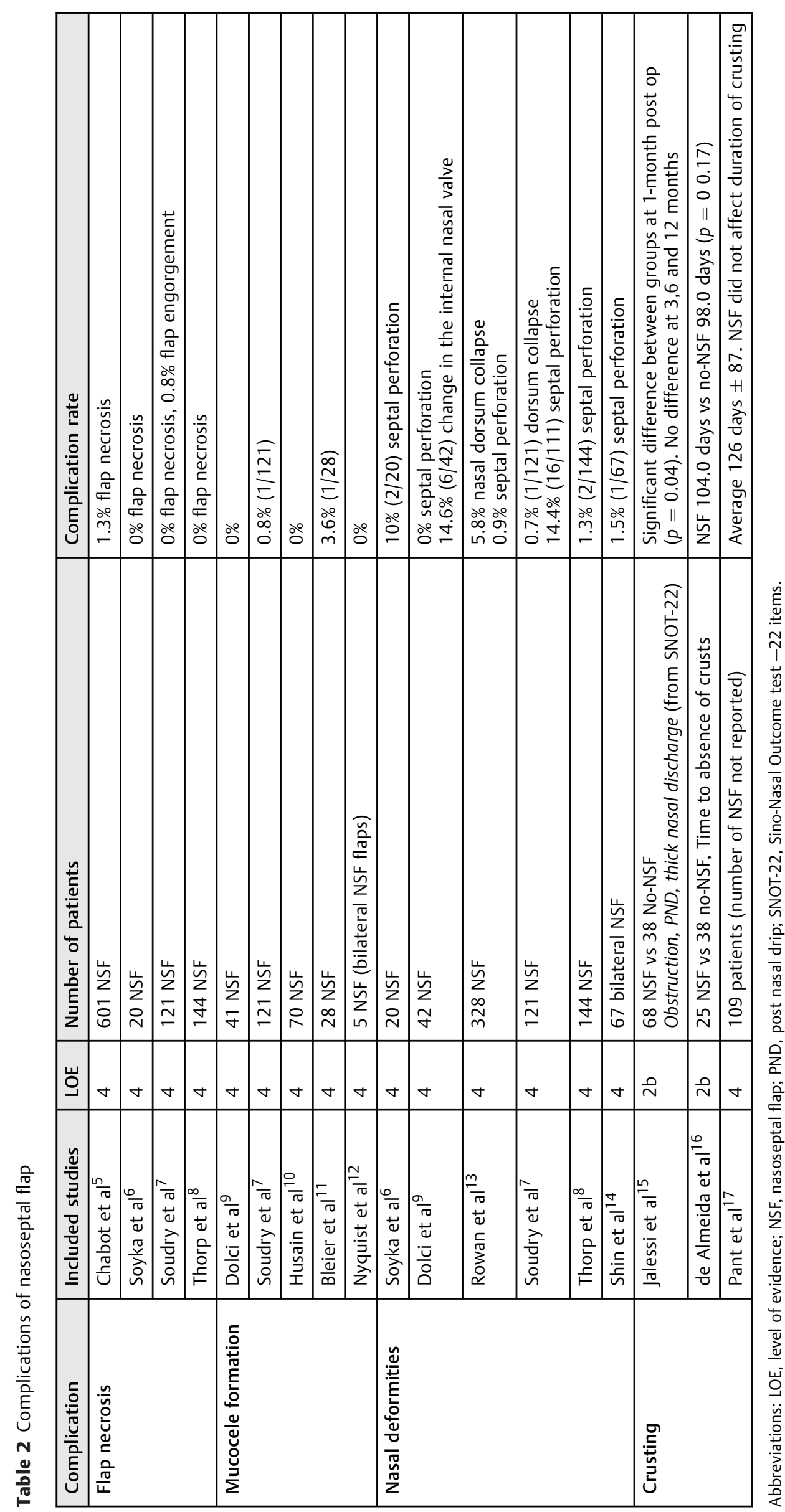

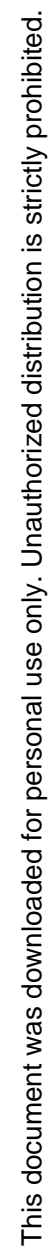




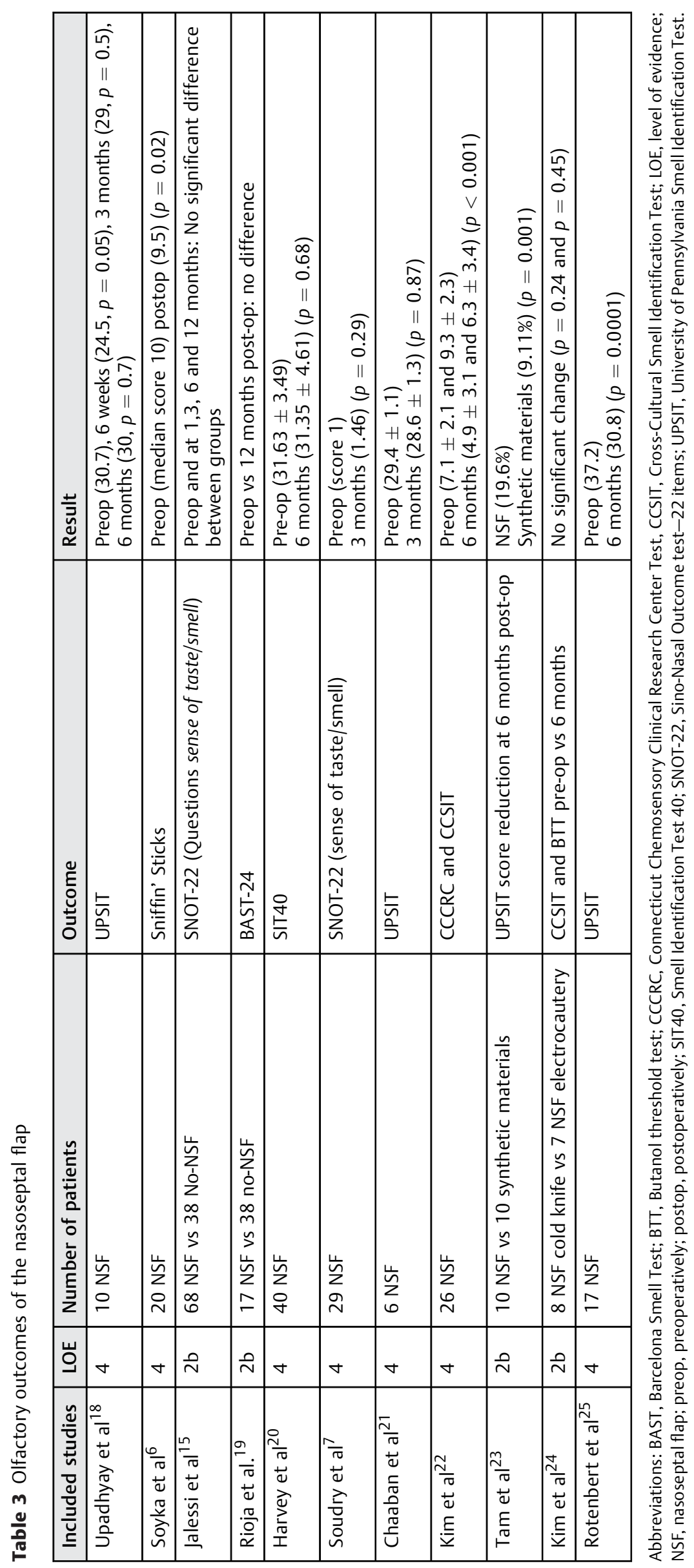




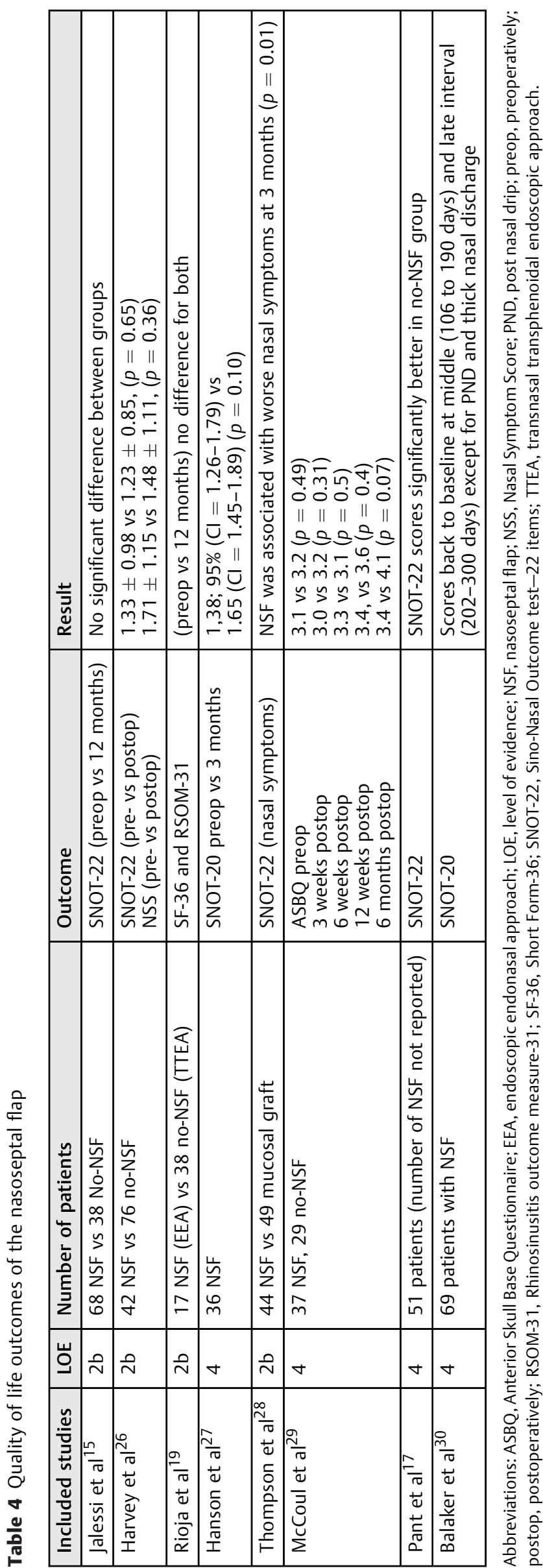

baseline $(30.71 \pm 5.5)(p=0.05)$. However, at 3 months and 6 months follow-up, the scores were back to the preoperative levels $(29.0 \pm 3.7$ and $30.0 \pm 3.9$, respectively). In the free mucosal graft group, there was no significant reduction in UPSIT scores postoperatively. Other series that describe comparable olfactory strip preservation techniques found similar results with complete recovery of olfaction by 6 months. ${ }^{7,19,20}$ Kim et al compared the effect of electrocautery to cold knife dissection of the NSF and found increased epithelial damage in the former, but no significant difference in olfaction. ${ }^{24}$-Table 3 presents additional studies included in this review.

\section{Prolonged Crusting}

When an NSF is harvested, septal cartilage and bone remain exposed to the nasal cavity. It has been hypothesized that reepithelialization of the exposed cartilage and bone results in a prolonged duration of healing. de Almeida et al investigated the time to resolution of nasal crusting, comparing an NSF cohort to patients who did not have an NSF. ${ }^{16}$ Patients who had an NSF did not have a significantly longer time to recovery (median 104 days; 95\% confidence interval [CI], 81.3-126.7) than patients without an NSF (98.0; CI, 84.6111.4). Their analysis did not identify any independent factors associated with prolonged crusting in EES (age, sex, radiation therapy, chemotherapy, surgical complexity, and use of fat graft). Similarly, Pant et al found no difference in duration of crusting between cohorts. ${ }^{17}$ Jalessi et al used the test items, Obstruction, Post Nasal Discharge, and Thick Nasal Discharge from the Sino-Nasal Outcome test-22 items (SNOT-22) as surrogate markers for nasal crusting. ${ }^{15}$ They found a significantly higher score in the NSF group at 1 month ( $p=0.04)$ and no difference at 3, 6, and 12 months. These studies are presented in - Table 2 .

\section{Nasal Deformity}

Three published articles discussed the rates of septal perforation and dorsal nasal collapse (saddle nose) associated with the use of an NSF. Rowan et al found a 5.8\% rate of dorsum collapse and a $0.9 \%$ rate of septal perforation. ${ }^{13}$ Soyka et al and Soudry et al found rates of septal perforation of 14.4 and $10 \%$, respectively. ${ }^{6,7}$

\section{Quality of Life Outcomes (QoL)}

Several studies have investigated the impact of the NSF on QoL outcomes (-Table 4). The two largest series were published by Jalessi et al and Harvey et al and included 106 and 108 patients, respectively. ${ }^{15,26}$ Both studies used the SNOT-22 questionnaire and found no difference in QoL outcomes while comparing the use of an NSF to other multilayer reconstructive methods. One study found a significant difference at 3 months in nasal symptoms (subset from SNOT-22) while comparing the NSF to free mucosal graft reconstruction. ${ }^{28}$

\section{Quality of Evidence}

Risk of bias was assessed using the Cochrane Collaboration Effective Practice and Organization of Care (EPOC) tool for 

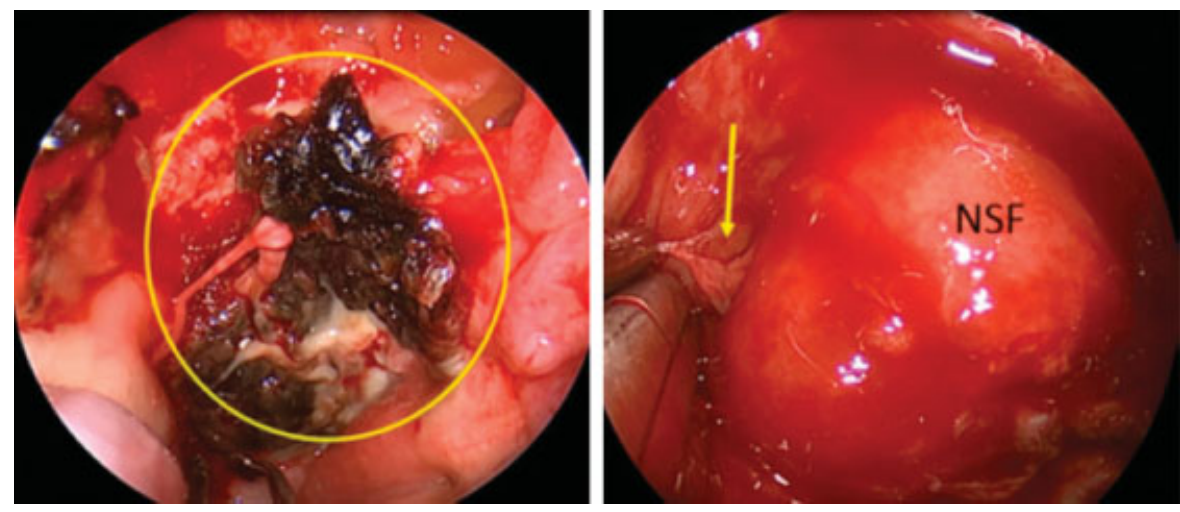

Fig. 2 Nasoseptal flap necrosis. Left: Intraoperative endoscopic view of a necrotic NSF (circle). Right: Normal NSF with CSF leak (arrow). (Adapted from Chabot et al, $2018^{5}$ ). CSF, cerebrospinal fluid; NSF, nasoseptal flap.

assessing risk of bias (-Table 5). Quality of evidence was assessed using the Grading of Recommendations Assessment, Development and Evaluation (GRADE) system for transparency and simplicity. ${ }^{31,32}$ This only applied to studies that included a comparative group. ${ }^{15-17,19,23,24,26}$ There were no high quality randomized controlled trials providing high quality evidence. Studies were qualified as moderate quality $^{16,20,23}$ or low quality ${ }^{15,19,24,29}$ based on their design, risk of bias, effect size, and inconsistency of results.

\section{Discussion}

The NSF receives vascularization from the posterior septal artery (PSA), a terminal branch of the sphenopalatine artery. The PSA itself divides into two branches as it courses across the anterior wall of the sphenoid sinus, before reaching the posterior nasal septum (-Fig. 3). ${ }^{33}$ Placement of incisions and NSF harvesting technique are thus of great importance to protect this vascular supply. The superior incision must be placed at the superior aspect of the sphenoid ostium to protect the superior branch of the PSA. It is then drawn parallel to the skull base, at least $1 \mathrm{~cm}$ below the skull base. Once anterior to the olfactory epithelium, the incision can curve superiorly toward the superior limit of the septum, to increase flap size. Retrospectively, comparing NSF reconstruction with free mucosal graft reconstruction is inherently biased by patient selection and disease severity. Yet, series that described olfactory strip preservation technique have shown low rates of olfactory loss, with return to baseline olfaction within 3 to 6 months. ${ }^{6,7,15,18-21,24}$ Intact vascular supply of the flap pedicle and perfusion can be confirmed prior to harvest with Doppler ultrasound or Indocyanine Green fluoroscopy (under investigation), and postoperatively on MRI examination ${ }^{5,34,35}$ (-Fig. 4). It is important not to confuse postoperative NSF enhancement on MRI with tumor residual/recurrence. ${ }^{36}$ Prior septal surgery does not jeopardize NSF vascularization. ${ }^{37}$ The axial pattern of vascularization is preserved postseptoplasty, and secondary NSF harvest with revision cases, as flap take-down and reuse, has been shown to be safe and reliable. ${ }^{5,38}$ A limited number of studies have reported postoperative rates of NSF necrosis (-Table $\mathbf{2}$ ). While the reported rate varies between 0 and $1.3 \%$, it is likely that this complication often goes unnoticed when the patient has a normal postoperative course, resulting in underreporting. Similarly, septal perforation and nasal dorsum collapse are rare. Reported rates of septal perforation vary between 0 and $14.4 \%$. Removal of the posterior septum during surgery (posterior septectomy) is rarely noticeable to patients, and anterior septal perforations, if symptomatic, can be closed surgically or with a septal button. Only two identified studies report rates of dorsum collapse ( 0.7 and $5.8 \%$ ). Considering the lack of standardized measures for dorsal collapse and its rarity, it is likely that this complication is also underreported. ${ }^{7,13}$

Table 5 Risk for bias assessment

\begin{tabular}{|c|c|c|c|c|c|c|}
\hline Study & $\begin{array}{l}\text { Selection of } \\
\text { participants }\end{array}$ & $\begin{array}{l}\text { Confounding } \\
\text { variables }\end{array}$ & $\begin{array}{l}\text { Intervention } \\
\text { measurement }\end{array}$ & $\begin{array}{l}\text { Blinding of } \\
\text { outcome } \\
\text { assessment }\end{array}$ & $\begin{array}{l}\text { Incomplete } \\
\text { outcome } \\
\text { data }\end{array}$ & $\begin{array}{l}\text { Selective } \\
\text { outcome } \\
\text { reporting }\end{array}$ \\
\hline Jalessi et al ${ }^{15}$ & - & - & + & - & + & $?$ \\
\hline Harvey et $\mathrm{al}^{26}$ & + & + & + & - & + & + \\
\hline Rioja et al $^{19}$ & - & - & + & - & + & + \\
\hline Tam et $\mathrm{a}^{23}$ & + & - & + & - & + & + \\
\hline Kim et $\mathrm{al}^{24}$ & - & - & + & - & + & $?$ \\
\hline Thompson et al ${ }^{28}$ & - & - & + & - & $?$ & - \\
\hline
\end{tabular}

+ , low risk of bias; -, high risk of bias; ?, unclear. 


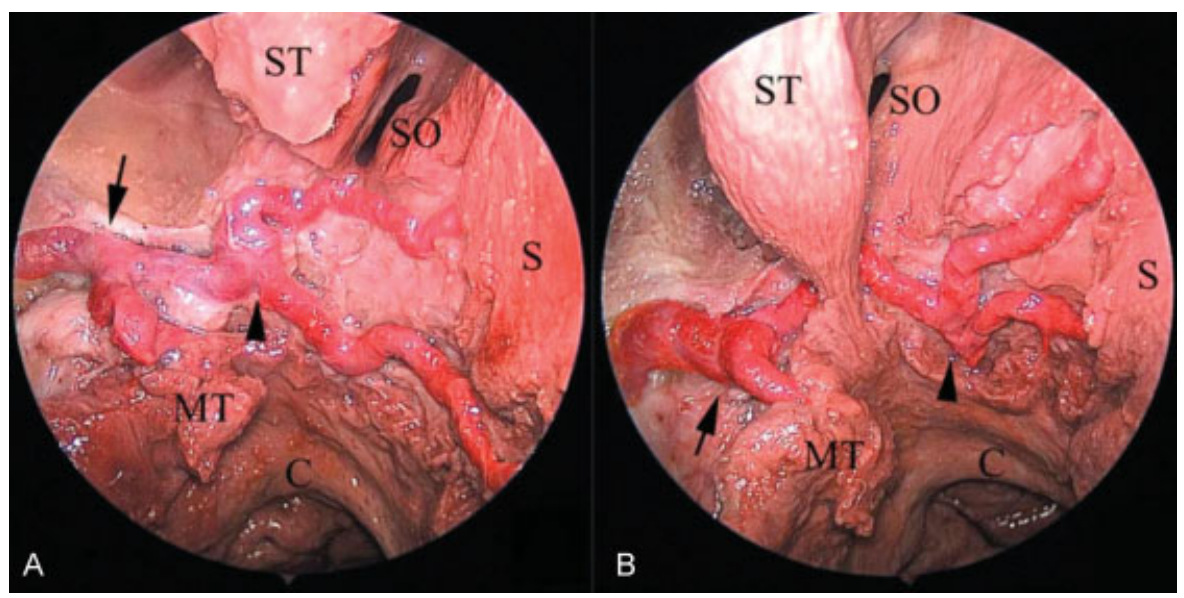

Fig. 3 Branching of the posterior nasal artery. Endoscopic view of the sphenoidal bifurcation of the sphenopalatine artery and posterior septal artery in an anatomical dissection (right side). The posterior septal artery bifurcation can be lateral (seen in A) or medial (seen in B) to the sphenoid ostium. Black arrow: Sphenopalatine artery bifurcation; black arrowhead: posterior septal artery bifurcation.. (Reprinted with permission from Zhang et al, $2015^{34}$ ). C, choana; MT, middle turbinate; S, septum; SO, sphenoid ostium; ST, superior turbinate.

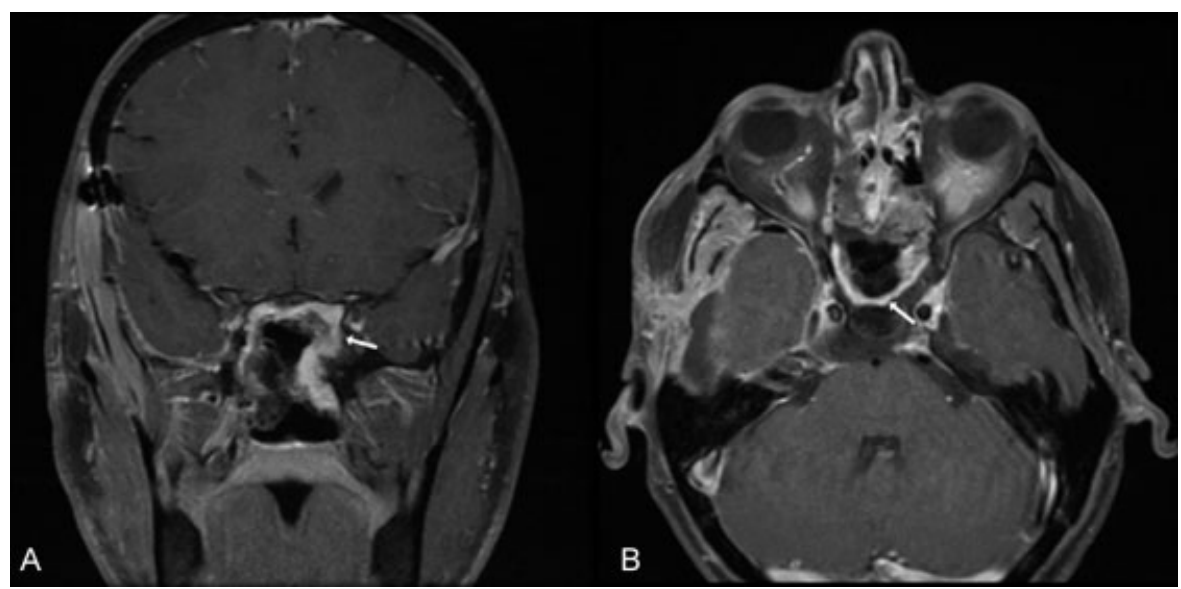

Fig. 4 Postoperative NSF enhancement. Coronal (A) and axial (B) views of a postoperative T1 gadolinium-enhanced MRI, both demonstrating flap enhancement (white arrows). MRI, magnetic resonance imaging; NSF, nasoseptal flap.

Factors contributing to nasal dorsum collapse have not been fully elucidated.

Several factors have been shown to affect postoperative QoL measurements in endoscopic skull base surgery. Harvey et al showed that preoperative radiation therapy, extent of surgery, and malignant tumor pathology were more important contributors to morbidity than the use of an $\mathrm{NSF}^{26}$ It is important to note that these factors were not accounted for in other studies that suggest increased morbidity with the use of an $\mathrm{NSF}^{39}$ The NSF donor site heals by secondary intention and can result in significant crusting for up to 12 weeks postoperatively. ${ }^{16,27,40}$ While septal crusting may not last any longer than the expected postoperative sinonasal crusting, ${ }^{16,41}$ it can affect the internal nasal valve and contribute to symptomatic nasal obstruction. Several solutions to expedite septal healing have been described, such as silicone splinting, free grafting (mucosa or fascia lata), and the reverse rotation flap described by Caicedo et $\mathrm{al}^{41-43}$ Overall, the quality of evidence is low with most studies designed as cohort studies with high potential for selection bias (-Table 5) or case series. ${ }^{15,17,19,26-30}$ However, the use of an NSF does not appear to alter QoL in the long term, but can increase nasal crusting and obstruction within the first 6 weeks to 3 months.

\section{Conclusion}

The NSF is a robust and reliable reconstructive flap in EES of the skull base. Multiple series have demonstrated its efficacy in reducing CSF leak rates. This systematic review of the literature further supports its safety in endoscopic skull base surgery, showing low rates of reported complications. We hypothesize that some of these complications, such as NSF necrosis and dorsal collapse are likely underreported. The NSF is only one option in the skull base reconstructive ladder, and its use in preventing CSF leaks and covering neurovascular structures must be balanced against its potential morbidities. 


\section{Conflicts of Interest}

None.

\section{References}

1 Hadad G, Bassagasteguy L, Carrau RL, et al. A novel reconstructive technique after endoscopic expanded endonasal approaches: vascular pedicle nasoseptal flap. Laryngoscope 2006;116(10): $1882-1886$

2 Hirsch 0 . Successful closure of cere brospinal fluid rhinorrhea by endonasal surgery. AMA Arch Otolaryngol 1952;56(01):1-12

3 Harvey RJ, Parmar P, Sacks R, Zanation AM. Endoscopic skull base reconstruction of large dural defects: a systematic review of published evidence. Laryngoscope 2012;122(02):452-459

4 Zanation AM, Carrau RL, Snyderman CH, et al. Nasoseptal flap reconstruction of high flow intraoperative cerebral spinal fluid leaks during endoscopic skull base surgery. Am J Rhinol Allergy 2009;23(05):518-521

5 Chabot JD, Patel CR, Hughes MA, et al. Nasoseptal flap necrosis: a rare complication of endoscopic endonasal surgery. J Neurosurg 2018;128(05):1463-1472

6 Soyka MB, Serra C, Regli L, Meier E, Holzmann D. Long-term olfactory outcome after nasoseptal flap reconstructions in midline skull base surgery. Am J Rhinol Allergy 2017;31(05):334-337

7 Soudry E, Psaltis AJ, Lee KH, Vaezafshar R, Nayak JV, Hwang PH. Complications associated with the pedicled nasoseptal flap for skull base reconstruction. Laryngoscope 2015;125(01):80-85

8 Thorp BD, Sreenath SB, Ebert CS, Zanation AM. Endoscopic skull base reconstruction: a review and clinical case series of 152 vascularized flaps used for surgical skull base defects in the setting of intraoperative cerebrospinal fluid leak. Neurosurg Focus 2014;37(04):E4

9 Dolci RLL, Miyake MM, Tateno DA, et al. Postoperative otorhinolaryngologic complications in transnasal endoscopic surgery to access the skull base. Rev Bras Otorrinolaringol (Engl Ed) 2017;83 (03):349-355

10 Husain Q Sanghvi S, Kovalerchik O, et al. Assessment of mucocele formation after endoscopic nasoseptal flap reconstruction of skull base defects. Allergy Rhinol (Providence) 2013;4(01): e27-e31

11 Bleier BS, Wang EW, Vandergrift WA III, Schlosser RJ. Mucocele rate after endoscopic skull base reconstruction using vascularized pedicled flaps. Am J Rhinol Allergy 2011;25(03):186-187

12 Nyquist GG, Anand VK, Singh A, Schwartz TH. Janus flap: bilateral nasoseptal flaps for anterior skull base reconstruction. Otolaryngol Head Neck Surg 2010;142(03):327-331

13 Rowan NR, Wang EW, Gardner PA, Fernandez-Miranda JC, Snyderman $\mathrm{CH}$. Nasal deformities following nasoseptal flap reconstruction of skull base defects. J Neurol Surg B Skull Base 2016;77(01): 14-18

14 Shin JH, Kang SG, Kim SW, et al. Bilateral nasoseptal flaps for endoscopic endonasal transsphenoidal approach. J Craniofac Surg 2013;24(05):1569-1572

15 Jalessi M, Jahanbakhshi A, Amini E, Kamrava SK, Farhadi M. Impact of nasoseptal flap elevation on sinonasal quality of life in endoscopic endonasal approach to pituitary adenomas. Eur Arch Otorhinolaryngol 2016;273(05):1199-1205

16 de Almeida JR, Snyderman CH, Gardner PA, Carrau RL, Vescan AD. Nasal morbidity following endoscopic skull base surgery: a prospective cohort study. Head Neck 2011;33(04):547-551

17 Pant H, Bhatki AM, Snyderman CH, et al. Quality of life following endonasal skull base surgery. Skull Base 2010;20(01):35-40

18 Upadhyay S, Buohliqah L, Dolci RLL, Otto BA, Prevedello DM, Carrau RL. Periodic olfactory assessment in patients undergoing skull base surgery with preservation of the olfactory strip. Laryngoscope 2017;127(09):1970-1975

19 Rioja E, Bernal-Sprekelsen M, Enriquez K, et al. Long-term outcomes of endoscopic endonasal approach for skull base surgery: a prospective study. Eur Arch Otorhinolaryngol 2016;273(07): 1809-1817

20 Harvey RJ, Winder M, Davidson A, et al. The olfactory strip and its preservation in endoscopic pituitary surgery maintains smell and sinonasal function. J Neurol Surg B Skull Base 2015;76(06): 464-470

21 Chaaban MR, Chaudhry AL, Riley KO, Woodworth BA. Objective assessment of olfaction after transsphenoidal pituitary surgery. Am J Rhinol Allergy 2015;29(05):365-368

22 Kim BY, Kang SG, Kim SW, et al. Olfactory changes after endoscopic endonasal transsphenoidal approach for skull base tumors. Laryngoscope 2014;124(11):2470-2475

23 Tam S, Duggal N, Rotenberg BW. Olfactory outcomes following endoscopic pituitary surgery with or without septal flap reconstruction: a randomized controlled trial. Int Forum Allergy Rhinol 2013;3(01):62-65

24 Kim SW, Park KB, Khalmuratova R, Lee HK, Jeon SY, Kim DW. Clinical and histologic studies of olfactory outcomes after nasoseptal flap harvesting. Laryngoscope 2013;123(07): 1602-1606

25 Rotenberg BW, Saunders S, Duggal N. Olfactory outcomes after endoscopic transsphenoidal pituitary surgery. Laryngoscope 2011;121(08):1611-1613

26 Harvey RJ, Malek J, Winder M, et al. Sinonasal morbidity following tumour resection with and without nasoseptal flap reconstruction. Rhinology 2015;53(02):122-128

27 Hanson M, Patel PM, Betz C, Olson S, Panizza B, Wallwork B. Sinonasal outcomes following endoscopic anterior skull base surgery with nasoseptal flap reconstruction: a prospective study. J Laryngol Otol 2015;129(Suppl 3):S41-S46

28 Thompson CF, Suh JD, Liu Y, Bergsneider M, Wang MB. Modifications to the endoscopic approach for anterior skull base lesions improve postoperative sinonasal symptoms. J Neurol Surg B Skull Base 2014;75(01):65-72

29 McCoul ED, Anand VK, Schwartz TH. Improvements in site-specific quality of life 6 months after endoscopic anterior skull base surgery: a prospective study. J Neurosurg 2012;117(03):498-506

30 Balaker AE, Bergsneider M, Martin NA, Wang MB. Evolution of sinonasal symptoms following endoscopic anterior skull base surgery. Skull Base 2010;20(04):245-251

31 Guyatt GH, Oxman AD, Vist GE, et al; GRADE Working Group. GRADE: an emerging consensus on rating quality of evidence and strength of recommendations. BMJ 2008;336(7650):924-926

32 Atkins D, Eccles M, Flottorp S, et al; GRADE Working Group. Systems for grading the quality of evidence and the strength of recommendations I: critical appraisal of existing approaches the GRADE Working Group. BMC Health Serv Res 2004;4(01):38

33 Zhang X, Wang EW, Wei H, et al. Anatomy of the posterior septal artery with surgical implications on the vascularized pedicled nasoseptal flap. Head Neck 2015;37(10):1470-1476

34 Kerr EE, Jamshidi A, Carrau RL, et al. Indocyanine green fluorescence to evaluate nasoseptal flap viability in endoscopic endonasal cranial base surgery. J Neurol Surg B Skull Base 2017;78(05): 408-412

35 Learned KO, Adappa ND, Loevner LA, Palmer JN, Newman JG, Lee JY. MR imaging evaluation of endoscopic cranial base reconstruction with pedicled nasoseptal flap following endoscopic endonasal skull base surgery. Eur J Radiol 2013;82(03):544-551

36 Walsh E, Illing E, Riley KO, et al. Inaccurate assessments of anterior cranial base malignancy following nasoseptal flap reconstruction. J Neurol Surg B Skull Base 2015;76(05):385-389

37 Park W, Hong SD, Nam DH, et al. Nasoseptal flap elevation in patients with history of septal surgery: does it increase flap failure or cerebrospinal fluid leakage? World Neurosurg 2016; 93:164-167

38 Zanation AM, Carrau RL, Snyderman $\mathrm{CH}$, et al. Nasoseptal flap takedown and reuse in revision endoscopic skull base reconstruction. Laryngoscope 2011;121(01):42-46 
39 Alobid I, Enseñat J, Mariño-Sánchez F, et al. Impairment of olfaction and mucociliary clearance after expanded endonasal approach using vascularized septal flap reconstruction for skull base tumors. Neurosurgery 2013;72(04):540-546

40 Yoo F, Kuan EC, Bergsneider M, Wang MB. Free mucosal graft reconstruction of the septum after nasoseptal flap harvest: a novel technique using a posterior septal free mucosal graft. J Neurol Surg B Skull Base 2017;78(02):201-206

41 Kimple AJ, Leight WD, Wheless SA, Zanation AM. Reducing nasal morbidity after skull base reconstruction with the nasoseptal flap: free middle turbinate mucosal grafts. Laryngoscope 2012; 122(09):1920-1924

42 Caicedo-Granados E, Carrau R, Snyderman CH, et al. Reverse rotation flap for reconstruction of donor site after vascular pedicled nasoseptal flap in skull base surgery. Laryngoscope 2010;120(08):1550-1552

43 Zeinalizadeh M, Sadrehosseini SM, Barkhoudarian G, Carrau RL. Reconstruction of the denuded nasoseptal flap donor site with a free fascia lata graft: technical note. Eur Arch Otorhinolaryngol 2016;273(10):3179-3182 